\title{
The Analysis of Forming Forces in Single Point Incremental Forming
}

\author{
Kyung Hee Koh ${ }^{1}$, Jae-Gwan Kang ${ }^{1}$ and Jong-Yun Jung ${ }^{2}$ \\ ${ }^{1}$ Division of Mechanical Engineering, Kyungnam University, Changwon, R. Korea \\ ${ }^{2}$ School of Industrial Engineering and Naval Architecture, Changwon National University, Changwon, R. Korea
}

\begin{abstract}
Incremental forming is a process to produce sheet metal parts in quick. Because there is no need for dedicated dies and molds, this process is less cost and time spent. The purpose of this study is to investigate forming forces in single point incremental forming. Producing a cone frustum of aluminum is tested for forming forces. A dynamometer is used to collect forming forces and analyze them. These forces are compared with cutting forces upon producing same geometrical shapes of experimental parts. The forming forces in $\mathrm{Z}$ direction are 40 times larger than the machining forces. A spindle and its axis of a forming machine should be designed enough to withstand the forming forces.
\end{abstract}

\section{Introduction}

Modern manufacturing requires higher product quality with shorter production time in order to get more profits in competitive markets. Metal forming produces parts in short time upon equipment setup. However, the process needs dies and moulds which are equipped with press machines. The preparation for the setup takes a lot of time for producing dies and moulds.

However, incremental forming does not need the dies and moulds because it forms a shape by gradually deforming materials. Incremental sheet metal forming without dies and moulds is economical because lessequipment is required and shorter production time is spent on. However, the forming forces are great when they are compared with the cutting forces for producing same geometrical shapes.

Research on incremental forming forces required for forming without any defects is not fully studied yet. This paper finds and analyses forming forces in single point incremental forming (SPIF). The pressure to a forming tool is forming force which is studied in this research.

Forming forces in sheet metal forming are important because excessive forming force causes flaws of tears to raw material because it is very thin. However, less force does not make designed shapes of geometries in metal forming. The purpose of this research is to measure forming forces which is expended to a forming tool in SPIF in order to find legitimate forming forces in avoiding flaws or incompleteness. In addition, this paper compares forming forces with cutting forces of same shapes which are required for machining. The results of this research can be used to design a forming machine in structural analysis.

\section{Incremental forming}

SPIF is a process that produces sheet metal part which is deformed along with gradual changes. This deformation is caused by strong compressional pressure applied to a forming tool of rigid body. Geometrical shapes are formed by a moving tool in layer by layer [1]. Fig. 1 shows a schematic diagram and conceptual description of incremental forming. Raw material, being a sheet metal, is deformed by great pressure of a tool on a forming machine in SPIF.

Movement of a forming tool on a forming machine is controlled by CNC (Computerized Numerical Control), which accurately produces mechanical parts as well as creative arts. Fig. 2 shows typical parts which are produced by incremental forming. Also, auto bodies such as door fenders or engine hoods in Fig. 3 are examples which can be produced by the process.

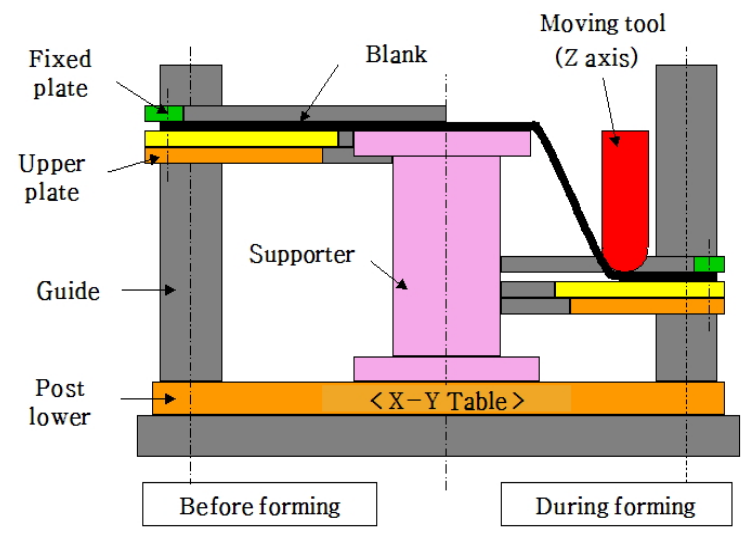

Figure 1. Schematic diagram of single point incremental forming. 

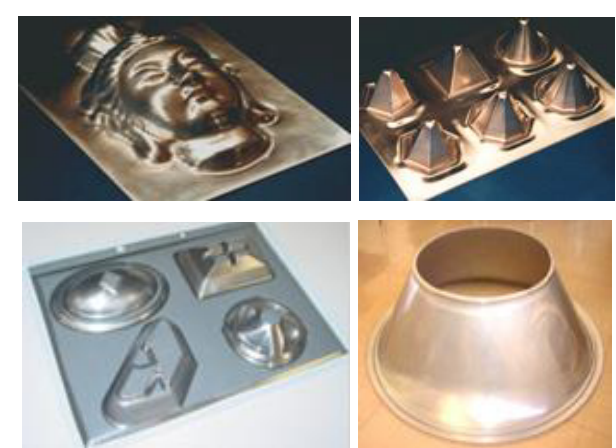

Figure 2. Various examples of formed parts by incremental forming.

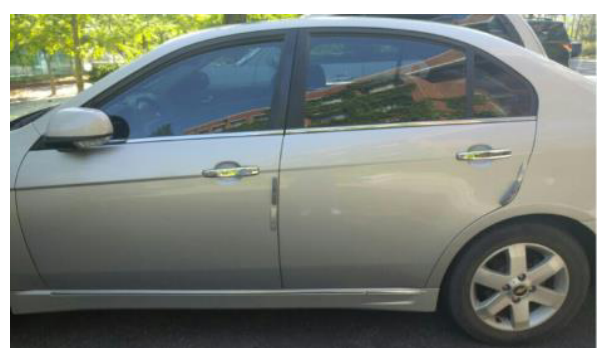

Figure 3. Fenders of an auto body.

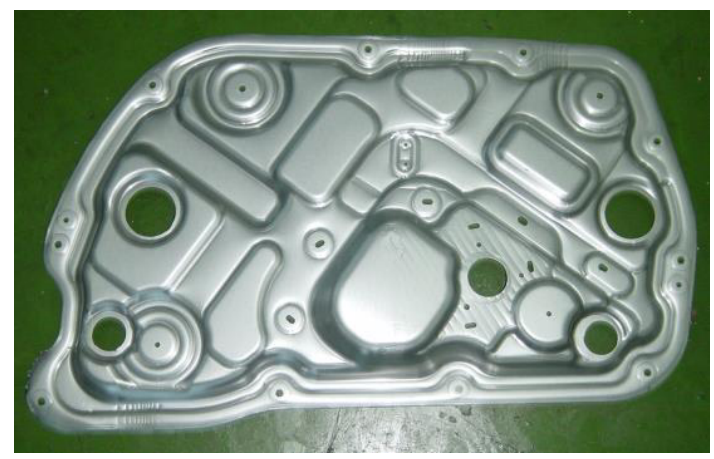

Figure 4. Door panel part produced by incremental forming.

The main advantage of incremental forming is that it does not need dedicated full pressing dies. In negative incremental forming, any die or supporter is not necessary. For particular cases of positive incremental forming, only a partial die or a supporter is needed under a sheet material in a forming machine.

A photo in Fig. 4 is a part produced by SPIF and is taken from inside an automobile door panel. A schematic diagram of a negative forming is shown in Fig. 5. In the figure, a tool pressing a blank raw material is moving $\mathrm{X}$ Y direction on a plane.

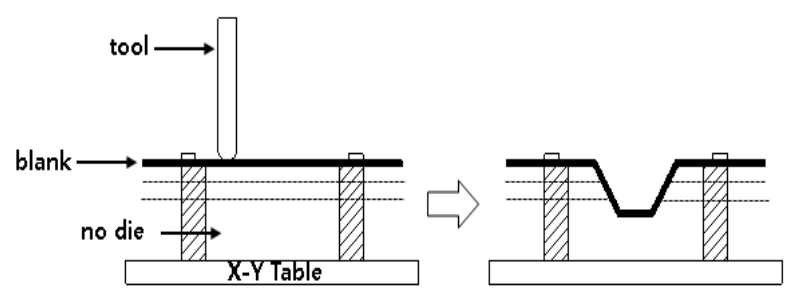

Figure 5. A schematic diagram of negative forming.

As stated in the previous research [1], [7], forming forces and accuracy greatly depend on process parameters. Tool path type for incremental forming is also an effective process parameter. There are two path types. One is constant $\mathrm{Z}$ or contoured type, the other is spiral or continuous type. Fig. 6 and 7 show two types of tool path which commonly utilized in SPIF.
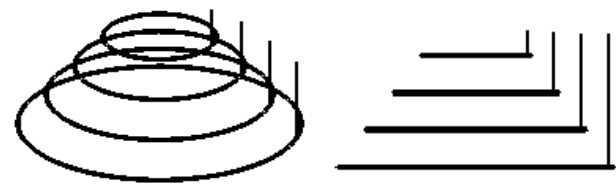

Figure 6. Contoured tool path.
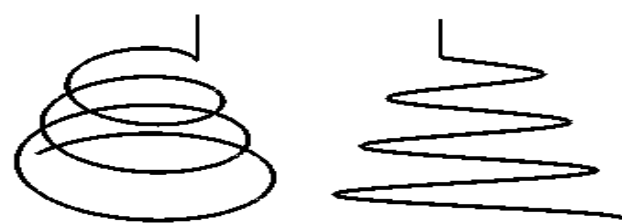

Figure 7. Spiral tool path.

Incremental forming research on mathematical model for forming forces was presented [2]. It suggested a mathematical model for prediction of forming forces in SPIF. It deduced equations through several experiments. Their results were compared with the ones resulted from Finite Element Method (FEM) software. Force prediction using FEM was published [3]. This study examined five different materials and had experimental results. From the result, they obtained regression formulae in order to compute axial and tangential forces in incremental forming. Other research on force analysis of SPIF was studied [4]. The research studied forming forces and formability, which was based on the incremental forming angle. They compared their results with previous work of negative tool path. Another research [5] presented a comparison of forming forces in SPIF with cutting forces. They concluded that forming forces in $\mathrm{Z}$ axis was greater than $\mathrm{X}, \mathrm{Y}$ axis. However, cutting forces in $\mathrm{Z}$ axis was the smallest one. Normally, forming forces were greater than machining forces. Research on forces analysis was published in [6]. It found that the forming forces were small when they were compared with deep drawing. The forming force was not depend on a part size, however, it was dependant to a wall angle or a forming angle. Online control of incremental forming through punch force monitoring was presented in [7]. There were various parameters in incremental forming such as sheet thickness, forming depth, tool diameter, and wall angle. They drew a force equation from regression analysis through various experiments. Forming force was strongly dependant to the process parameters adopted.

Various literatures on forming forces in single point incremental forming have been presented, however, a comparison between forming forces and machining forces are not presented yet. Thus, this research focuses on analysing forces arisen from forming and machining.

\section{Experiments}

This research forms CAD models for experiments of producing them applying both processes of SPIF and metal cutting. A raw material used for SPIF is aluminium 1050 of $0.8 \mathrm{~mm}$ thickness. The used forming machine is DLNC-PA manufactured by A Company. Strokes in X, Y, $\mathrm{Z}$ axis of the machine are $1000 \times 900 \times 300 \mathrm{~mm}$. 
The geometrical shape for the experiments used for this research is a cone frustum shown in Fig. 8 with the detail dimensions. Table 1 shows conditions of incremental forming for these experiments. A contoured method is applied to generate tool paths for incremental forming.

Table 1. Forming conditions.

\begin{tabular}{|l|l|}
\hline Incremantal Forming & Condition \\
\hline Forming Tool & Ball type $6 \mathrm{~mm}$ diameter \\
\hline Forming Feed & $1,000 \mathrm{~mm} / \mathrm{min}$ \\
\hline Step distance & $0.5 \mathrm{~mm} /$ path \\
\hline Material thickness & AL $10500.8 \mathrm{~mm}$ \\
\hline
\end{tabular}

This research adopts negative incremental forming, shown in Fig. 5, which does not need any dedicated dies. A pressing punch tool is moved and controlled by contoured tool path which is shown in Fig. 6.

While the raw material of aluminium is being deformed, forming forces are collected and measured through using a dynamometer. The schematic diagram for the measurement of datum collection is shown in Fig. 9.
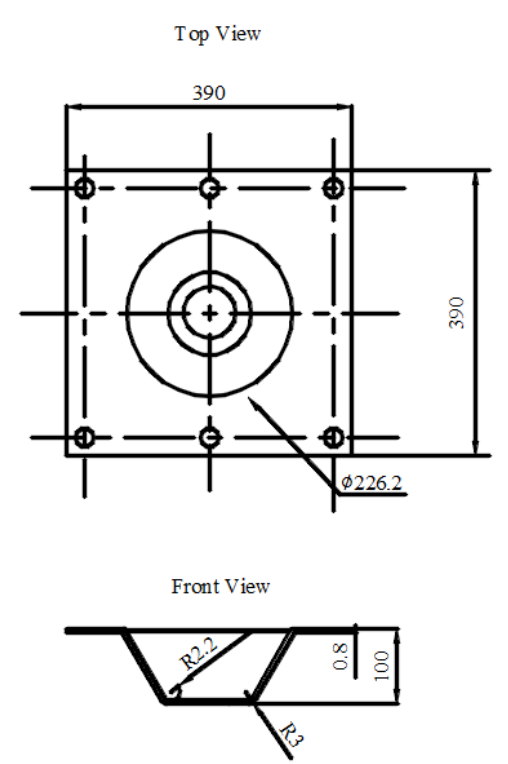

Figure 8. Cone frustum for experiments.

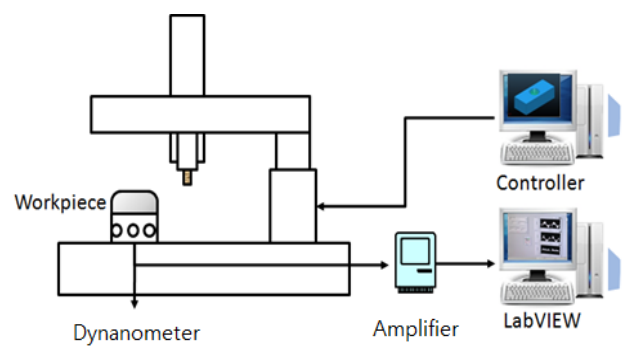

Figure 9. Schematic diagram of datum collection.

The machining forces are also collected while a high speed machining centre cuts an aluminium 1050 block. The machining conditions are shown in Table 2. The cutting forces are also collected and this paper compares the forming forces with the cutting forces.
Table 2. Machining conditions.

\begin{tabular}{|l|l|}
\hline Machining & Condition \\
\hline Cutting tool & $\begin{array}{c}\text { Ball end-mill } 6 \mathrm{~mm} \\
\text { diameter }\end{array}$ \\
\hline Cutting feed & $1,000 \mathrm{~mm} / \mathrm{min}$ \\
\hline Cutting depth & $0.5 \mathrm{~mm}$ \\
\hline Cutting speed & $10,000 \mathrm{rpm}$ \\
\hline Cutting material & AL1050 block \\
\hline
\end{tabular}

\section{Experimental results}

A shot of formed part by incremental forming is shown in Fig. 10. The collected data for forming forces are plotted in Fig. 11. $\mathrm{Z}$ direction in the figure is an axis of a forming tool. From the figure, the forces in $\mathrm{X}, \mathrm{Y}$ direction form sine waves in a distinct time. The curves shape in both positive and negative region while $\mathrm{Z}$ directional curve is plotted only in positive. The cutting forces of the experimental part are plotted in Fig. 12. The frequencies of the cutting forces are much higher than those of the forming forces. This is because that a cutting tool revolves around $\mathrm{Z}$ axis while a forming tool does not.

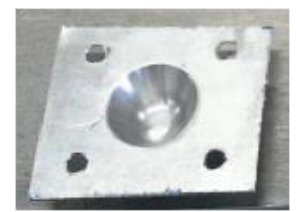

Figure 10. Experimental part formed by incremental forming.

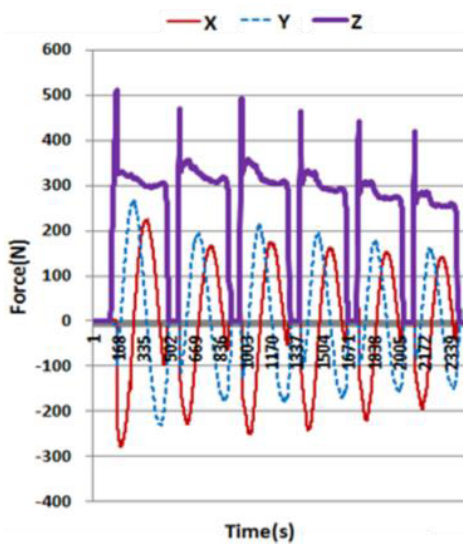

Figure 11. Forming forces in $X, Y, Z$ axis.

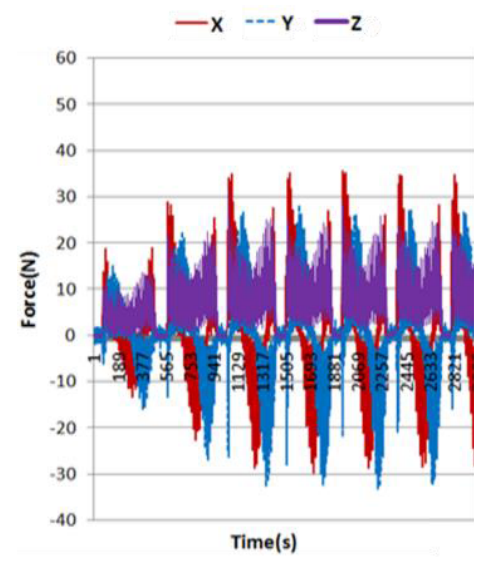

Figure 12. Cutting forces in $X, Y, Z$ axis. 


\section{Conclusions and future research}

This paper presents forming forces in SPIF. The forming forces in $\mathrm{Z}$ direction for producing a cone frustum are larger than 300 Newtons in positive. The magnitudes of forces in $\mathrm{Y}$ and $\mathrm{Z}$ direction are similar to each other but their phases are different. The shapes of both forces trace sine waves. Since the tool path type in the experiments is contour, the forces are distinctly divided in cycle by cycle. The magnitudes of the forming forces in $\mathrm{X}$ and $\mathrm{Y}$ direction are about 10 times larger than those of the machining forces. However, the forming forces in $\mathrm{Z}$ direction require 40 times greater than those in machining. The forming forces in $\mathrm{X}, \mathrm{Y}, \mathrm{Z}$ direction have trends to be declined in the figure 11. This is supposed that deformed area of raw material becomes smaller. However, machining forces are almost constant in all directions of axis.

These results give information that forming requires a lot of forces and energies. When a forming machine is designed, structures of the machine should be strong enough to sustain forming forces. A spindle and its axis, frames, holding devices, and other major elements should be robust to withstand forming forces. In addition, joints in forming machine must be strong enough to hold a punch tool to deform raw material. This is true that the thicker a raw material is, the greater forming forces are.

Forming forces for other different geometrical shapes and different materials are studied for future research. The possible geometrical shape is a frustum of quadrangular pyramid. These forming forces can be compared with cutting forces for same geometrical shapes of experiments. Forming forces and machining forces resulted from this research are analysed and compared with ones from a future research.

\section{References}

1. J. Kang, J. Jung, "Effective process parameters on shape dimensional accuracy in incremental sheet metal forming," Journal of Society Korea Industrial and Systems Engineering, vol. 38, no. 4 (Dec. 2015), pp. 177-183, doi:10.11627/ jkise.2015.38.4.177

2. B. Adrian, B. Octavian, O. Valentin, R. Gabriel, "Mathematical model for determining the forces in SPIF", Proc. International Conference on Manufacturing Science and Education, (2011)

3. R. Aerens, P. Eyckens, A. Van Bael, J.R. Duflou, "Force prediction for SPIF deuced from experimental and FEM observations", International Journal of Advanced Manufacturing Technology, doi: 10.1007/s00170-009-2160-2.

4. A. Fiorentino, E. Ceretti, A. Attanasio, L. Mazzoni, C. Giardini, "Ayalysis of forces, accuracy and formability in positive die sheet incremental forming", International Journal of Material Forum, vol. 2, (2009), pp. 805-808, doi: 10.1007/s12289009-0467-z

5. K. Koh, "Comparison between forming and cutting forces in incremental sheet metal forming and metal cutting processes", Unpublished thesis, Kyungnam University, (Jun. 2014)

6. A. Petek, K. Kuzman, J. Kopac, "Deformations and forces analysis of single point incremental sheet metal forming", Archives of Materials Science and Engineering, vol. 2, (2009), pp. 107-116.

7. L. Filice, G. Ambrogio, F. Micari, "CIRP Annals Manufacturing Technology, vol. 55, Issue 1, (2006), pp. 245-248. 